\title{
Sensibilidades em transformação: o enfrentamento à violência sexual na UFPR
}

\author{
Fernanda Azeredo de Moraes
}

Ao longo da última década, pautas e bandeiras feministas se popularizaram, alcançando importante aderência junto à juventude. Como aponta pesquisa conduzida pela Fundação Perseu Abramo (2010), entre 2001 e 2010 houve um aumento de 10\% no número de brasileiras que se consideram feministas (31\%). A identidade é ainda mais presente entre jovens de 15 a 17 anos (40\%), número que pode ser maior se cruzado com outros indicadores, como escolaridade e região.

A juventude emerge como um lugar político dentro do feminismo (Maluf 2006), muitas vezes através de uma trajetória comum: já sensibilizadas por discussões virtuais sobre o tema, é nas universidades onde as jovens estudantes têm acesso aos estudos de gênero, à teoria feminista e ao que aqui nos é mais relevante: a militância e os coletivos feministas. Contudo, o ensino superior não é vivido por elas apenas como lugar de aprendizado, mas também como um espaço de hierarquias tradicionais e estruturas patriarcais violentas. Nos Estados Unidos, estima-se que um quarto das estudantes universitárias já sofreram o chamado "campus rape" . As denúncias de estudantes da UFPR elencadas no relato a seguir demonstram que agressões como essa parecem ser intrínsecas à cultura universitária.

Como professora substituta do Departamento de Antropologia nos anos de 2015 e 2016, acompanhei de um lugar privilegiado, ao mesmo tempo aproximado e distante, os embates dessa nova geração feminista dentro da Universidade Federal do Paraná. O objetivo desse texto ${ }^{2}$ é descrever uma série de eventos que ocorreram no final do primeiro semestre de 2015, envolvendo alunas, alunos, coletivos feministas, paredes, reitoria, professores e diretores de curso, em torno de denúncias relativas à violência sexual. Destacarei as transformações de sensibilidades envolvidas nesse processo e o lugar da universidade na reprodução, ou enfrentamento, de violências machistas.

1 Heloísa Buarque de Almeida, comunicação, 2015.

2 Uma versão inicial desse trabalho foi apresentada no GT 62 Formação em Antropologia e Práticas Educativas: gênero e sexualidades, na XI Reunión de Antropología del Mercosur, realizada em Montevidéo, em dezembro de 2015. Agradeço as contribuiçôes do grupo e também das colegas da UFPR Mariana Corrêa Azevedo, Amélia Siegel Corrêa e Lennita Ruggi. 


\section{Os casos}

No final de maio de 2015, casos envolvendo denúncias de machismo e violência sexual ganharam evidência na UFPR, através da militância de alunas de graduação de diferentes cursos. No dia 22 daquele mês, uma sexta-feira, foi promovida uma intervenção feminista por alunas ligadas à página de Facebook "Spotted feminista UFPR" no Campus Politécnico. Na chamada online, que acompanhava uma foto com os dizeres “Mulher, você tem voz!", lia-se:

Estejamos munidas de cartolinas, papéis, pincéis, canetões, cola e toda a força que nos leva a lutar contra opressões vivenciadas dentro e fora da UFPR. ... Esse será também um espaço de empoderamento: calouras, secundaristas, todas que se sintam desconfortáveis com o silenciamento/ abuso/ objetificação que encontram em seus cursos e CAs serão bem-vindas.

O evento produziu vários cartazes e êstencis com dizeres como: "O centro politécnico vai ser todo feminista”, “CAs machistas não passarão”, “Respeita as minas!”, entre muitos outros ${ }^{3}$ afixados no campus.

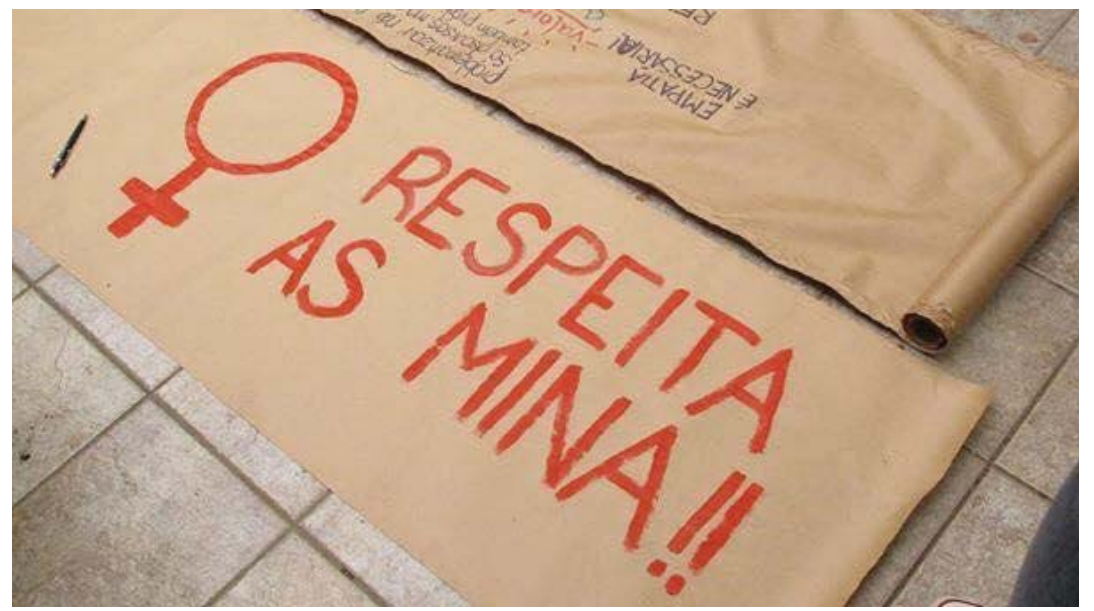

$\mathrm{Na}$ segunda-feira seguinte, na manhã do dia 25 , os cartazes foram encontrados rasgados e danificados. Um novo cartaz foi afixado, contendo os dizeres: "suas sapatas filhas da puta vou estourar suas bucetas e encher seus cus de porra!".

O Campus Politécnico ${ }^{4}$, como o próprio nome indica, agrega cursos de Ciências Exatas, Biológicas e o Setor de Tecnologia. A ação feminista realizada abertamente por alunas de diferentes cursos da universidade nas dependências do curso de Arquitetura e Urbanismo teve como réplica uma ação anônima, sexista e violenta de depredação dos cartazes e verbalização de ameaças. Como tréplica, no dia seguinte, as alunas se juntaram para mais um ato visual de cartazes e pichações feministas na "estufa”, espaço que já havia se tornado território de disputa.

3 Todas as imagens foram retiradas da página Spotted Feminista UFPR do Facebook

4 A f ragmentação dos campi da UFPR é uma informação relevante: espalhada em sete polos pela cidade, separados por áreas (humanas, saúde, tecnológicas...) a universidade não tem no seu cotidiano um caráter amplamente interdisciplinar, nem para o corpo discente, nem para o docente. 
De acordo com as manifestantes, durante o ato, seguranças da guarda patrimonial da universidade, o chefe do Departamento de Arquitetura e Urbanismo e alunos de cursos de engenharia tentaram retirar os cartazes e estêncis feministas, alegando vandalismo e depredação do patrimônio público. No mesmo dia, as alunas foram notificadas oficialmente pela chefia do Departamento de Arquitetura e Urbanismo, informando-as que deveriam limpar as intervenções até a tarde do dia seguinte, sob pena de instauração de um Procedimento Administrativo por danos ao Patrimônio Público.

A conservação do espaço físico ganhou preeminência sobre as disputas que nele ocorrem. Mais uma vez ameaçadas, eram as alunas que tinham seu status de estudantes da UFPR em risco, e não os autores das frases violentas, que permaneceram seguros no anonimato.

$\mathrm{Na}$ mesma semana, surgiam cartazes e pichações no Campus da Reitoria ${ }^{5}$ com palavras de ordem feministas e, especialmente, denúncias nomeando abusadores e estupradores entre o alunado (lia-se "Gustavo dos Santos Abusador" no elevador do prédio e nas paredes das rampas). O "escracho de machistas e agressores" - como foi denominado o movimento de denúncia pelas alunas - foi realizado por coletivos feministas dos cursos de História, Educação e Ciências Sociais.

De acordo com a nota postada pelo coletivo Quebrando Muros, reproduziram-se no campus Reitoria revides parecidos com aquela encontrada no campus Politécnico: pichações de conteúdo misógino e antifeminista foram feitas anonimamente, em banheiros, corredores e em especial, dentro da sala do Centro Acadêmico de Ciências Sociais (CACS) ${ }^{6}$. Idêntica foi também a reação da guarda terceirizada e de muitos funcionários: expressava-se uma maior revolta contra a "violência" perpetrada ao patrimônio público do que aquela vivida pelas alunas. Na página dos coletivos feministas no Facebook, surgiam comentários como: "pixar para defender o respeito é igual estuprar para defender a virgindade" ou "fazem protesto contra o machismo... enquanto cometem crimes por toda a UFPR... Lógica mandou saudades" ou ainda "Cartazes feministas = liberdade de expressão Cartazes antifeministas = agressividade e não é liberdade de expressão. Hahaha, se tratem”. As alunas feministas respondiam "Porque um estêncil feminista incomoda tanto?" e "Paredes em branco não lutam contra o machismo".

Em maio de 2015, tornou-se evidente que o embate estampado nas paredes era vivido cotidianamente pelas e pelos estudantes da universidade, longe da atenção da reitoria, do corpo docente e da coordenação dos cursos. A pichação, forma de expressão essencialmente disruptiva, surtia efeito: com o incômodo causado pela ação, as estudantes conseguiram dar voz e provocar ouvidos para o que é vivido "invisivelmente" na universidade. Mas a repercussão também as expunha, obrigando-as a buscar proteção institucional.

5 Onde se concentram os cursos de Educação, Filosofia, História, Ciências Sociais e Letras.

6 Disponível em: https://quebrandomuros.wordpress.com/2015/05/31/nota-de-solidariedade-as-mulheres-da-ufpr/ - acessado em Dezembro, 2015. 


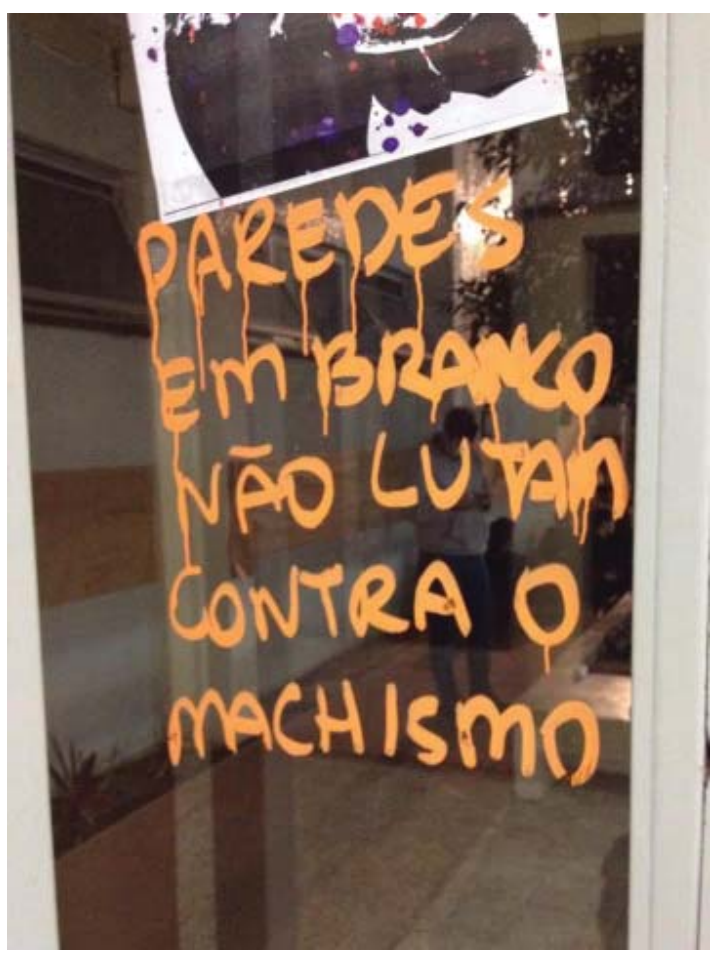

Na reitoria, uma das autoras das pichações de acusação contra o colega procurou ajuda da coordenação do curso de Ciências Sociais (do qual era acadêmica). Seu intuito não era o de fazer a denúncia do abuso de maneira formal, mas de buscar acolhimento. A estudante relatava que, após o "escracho", seus colegas de curso haviam se alinhado junto ao acusado de agressão. A demanda por acolhimento, seja por parte dos colegas ou da instituição, é apresentada como fundamental para a continuidade do curso por essas estudantes. As respostas institucionais esperadas pelas alunas - desligamento ou afastamento do agressor do curso - são, porém, institucionalmente inviáveis sem respaldo judicial (processo que leva, muitas vezes, mais tempo que um curso de graduação). Dessa forma, o amparo à vítima de agressão e o afastamento do autor da agressão do grupo se tornam uma "responsabilidade" das alunas e dos alunos em suas dinâmicas de convivência.

$\mathrm{Na}$ mesma semana, a coordenação do curso de Ciências Sociais foi novamente procurada por um outro aluno, com uma carta na mão. A carta havia sido fixada em uma parede entre os departamentos de Ciências Sociais e Letras. Ela trazia um "poema-denúncia" contra um estudante, identificado com as mesmas iniciais daquele que se apresentava, que teria violentado uma colega na sala de um centro acadêmico não indicado. $\mathrm{O}$ aluno, dizendo-se perseguido pelos colegas como personagem da carta, perguntava se "a coordenação do curso não iria tomar nenhuma providência?" e ameaçava tomar medidas legais.

Um último caso ajuda a compor o cenário daquele mês de maio: um estudante do PET (Programa de Educação Tutorial) de Ciências Sociais era acusado de fazer postagens machistas e de assediar colegas em festas e na sala de estudos. O grupo, apoiado pelo professor responsável, decidiu desligá-lo do programa, e consequentemente, de sua bolsa de iniciação científica. Frente à inépcia da instituição 
em responder (ou mesmo ouvir) as demandas de acolhimento às vítimas e responsabilização dos agressores, o alunado criava seus próprios mecanismos de correção.

\section{Reações “parainstitucionais"}

O caso dos cartazes no politécnico chegou ao jornal de maior circulação da capital paranaense (Gazeta do Povo) em manchetes como "Quando as universidades levarão o tema do estupro a sério? O caso da UFPR" e "Estudantes pedem que UFPR investigue ameaça de estupro". A polêmica se alastrou por blogs e redes sociais, exigindo da universidade e de seus diversos atores uma resposta rápida. Eventos em diferentes espaços universitários (de grêmios estudantis a reuniões com o vice-reitor) foram promovidos com o intuito de discutir e combater a violência denunciada.

No curso de Ciências Sociais, frente aos casos relatados à coordenação, foi promovida no dia 02 de junho uma reunião de alunas, alunos, professoras e professores com representantes do Núcleo de Promoção de Igualdade de Gênero (NUPIGE) do Ministério Público do Paraná7, com o intuito de apresentar a legislação existente relativa a crimes de violência sexual e de gênero, instruir sobre os caminhos e possibilidades legais de denúncia e ouvir as experiências de abuso das alunas, representadas pelos coletivos feministas. Já no momento da divulgação do evento houve a exigência por parte de algumas alunas de que o encontro fosse exclusivo para mulheres, alegando que apenas assim poderiam sentir-se seguras para relatarem suas experiências. Como era intenção da coordenação promover um evento que todos pudessem participar, optou-se por realizar a conversa em duas etapas, a primeira em um miniauditório de livre entrada, e a segunda, logo em seguida, em uma sala de aula, exclusiva para mulheres.

Nas duas instâncias da reunião com representantes do MP houve público máximo: 93 pessoas na etapa 1 e 56 alunas, professoras e pós-graduandas na etapa 2. Durante a conversa com a promotora Mariana Seifert Bazzo, ${ }^{8}$ ficou clara a principal questão para a maior parte das e dos participantes do encontro: o que é violência sexual? No que ela constitui?

No miniauditório lotado, as perguntas eram feitas pelas representantes dos coletivos feministas menos como uma forma de esclarecer dúvidas, e mais com o intuito de respaldar seus argumentos e denúncias frente aos colegas. O que era explicado pela promotora já parecia ser de conhecimento delas: de acordo com a Lei no 12.015, de 20099 , estupro é "Constranger alguém, mediante violência ou grave ameaça, a ter conjunção carnal ou a praticar ou permitir que com ele se pratique outro ato libidinoso".

Contudo, essa acepção do termo estupro não é a enraizada no senso comum, tanto de meios universitários quanto de delegacias (mesmo naquelas especializadas no atendimento de mulheres, como afirmam as alunas ${ }^{10}$ ). A definição legal de 1940, vigente até 2009 , que diferenciava estupro de atentado violento ao pudor e de outros crimes sexuais, definindo-o apenas como "conjunção carnal"

7 A articulação do Ministério Público do Paraná com a UFPR antecede esse evento e diz respeito a denúncias de racismo dentro da universidade, investigadas pelo MP estadual e apresentadas ao MP federal. Voltaremos a esse ponto mais a frente.

8 Acompanhada da assessora jurídica Camila Mafioletti Daltoe e da estagiária Kamila Anne Carvalho da Silva.

9 Disponível em: http://www.planalto.gov.br/ccivil_03/Decreto-Lei/Del2848.htm\#art213.

10 Para maiores discussões sobre as limitações das Delegacias da Mulher, ver: GREGORI, Maria Filomena. "Delegacias de Defesa da Mulher de São Paulo e as instituições: paradoxos e paralelismos". 
(penetração), entre homem e mulher, mediante o uso da força ou grave ameaça, segue no imaginário da maioria como definição do crime.

É interessante observar a apropriação estratégica feita pelas jovens feministas da nova letra da lei. A atualização jurídica e o novo feminismo parecem dizer respeito a um movimento de transformação de sensibilidades, no qual atitudes antes banalizadas e naturalizadas são vividas e tipificadas em sua violência, até então mascarada. Aquilo que, há pouco tempo, era caracterizado, nesse mesmo ambiente, como "besteira" é agora sentido e nomeado como estupro, para a perplexidade de parceiros, professores e colegas. É essa transformação de sensibilidades e padrões de relacionamento que está em andamento dentro do ambiente social universitário, uma transformação politizada e desestabilizadora.

Cabe igualmente destaque à dinâmica de relações entre alunado, corpo docente e universidade. Durante a segunda reunião com o Ministério Público, exclusiva para mulheres, foram muitas as falas que aludiam a um cenário desconhecido por professoras, professores, funcionários e funcionárias: sem se posicionarem individualmente como envolvidas em casos de abuso ou violência, as estudantes falavam no plural de experiências de amigas, colegas ou conhecidas que não eram relatadas à coordenação dos cursos ou a outras instâncias institucionais. Entre elas, havia a certeza de que se buscassem auxílio dentro da universidade não seriam ouvidas, ou que nenhuma medida seria tomada. Essa desconfiança institucional, fundamentada, como veremos mais à frente, por uma tradição de não posicionamento por parte da universidade, parece homogeneizar toda a diversidade de sujeitos atuantes na UFPR e caracterizar a perspectiva aqui adotada por muitas: a de que cabe a elas cuidarem uma das outras e produzirem justiça, e que a instituição não as representa.

Como coloca uma participante do coletivo feminista Aurora, fundado por alunas do curso de História da UFPR:

Eu vejo a universidade, querendo ou não, como uma autoridade. $\mathrm{O}$ reitor é uma autoridade, os professores são autoridades, e em toda a experiência que uma mulher tem em procurar autoridades não são experiências boas: procurar o estado para fazer leis que protegessem as mulheres não foi uma coisa realmente eficiente, procurar a polícia para punir o estuprador nunca é realmente eficiente. Então acho que muito do receio de procurar a universidade é porque a universidade não deixa de ser uma autoridade e porque você nunca sabe o que esperar da universidade. E acho que é mais difícil também conversar com pessoas que estão acima de você, sabe. Você tá expondo uma coisa que é completamente dilacerante para você, é muito mais fácil você falar sobre isso com pessoas próximas, pessoas iguais a você. E também tem a questão de que nunca há punição, né. $\mathrm{O}$ caso do Gustavo, ele continua frequentando o curso, continua frequentando a universidade... A Camila saiu da universidade, ela não está mais fazendo o curso, e ele continua aqui. Mesmo com a universidade tomando consciência do que aconteceu, nada aconteceu com ele. Então a autoridade da universidade foi tão falha quanto a autoridade do estado e a autoridade da polícia. E eu acho que enquanto isso continuar as pessoas vão continuar não contando para a universidade o que está acontecendo aqui dentro da universidade mesmo.... uma menina relatou um caso de estupro dentro da universidade e depois que ela viu que o caso da Camila não surtiu efeito ela não falou isso para a universidade. 
Frente à gravidade dos ocorridos e a necessidade de construção de novos canais de comunicação, algumas colegas e eu organizamos um evento continuado de reflexão sobre a violência sexual junto à comunidade universitária ${ }^{11}$. Encampadas na teoria feminista e com formação nas ciências sociais, tínhamos por intenção atingir alunas e alunos envolvidos nos embates acima narrados. Nossa posição de pós-graduandas e jovens professoras nos estimulava a procurar construir pontes entre o feminismo acadêmico e os novíssimos movimentos que surgem no contexto universitário ${ }^{12}$.

Para isso, organizamos uma série de três encontros intitulados "Rodas de conversa sobre violência sexual", realizados no campus da Reitoria nas tardes de sexta-feira no mês de junho, abertos à toda comunidade universitária. O plano era equipar as e os participantes com referenciais chaves da teoria feminista e dos estudos de gênero, de modo a enriquecer suas reflexóes e argumentos cotidianos, na universidade e fora dela. Para tal, organizamos os encontros em torno de três temas: sexualidade e cultura do estupro, masculinidades, participação e empoderamento.

Ao longo dos três encontros, contamos com a participação de 47 pessoas: alunas e alunos de graduação e pós-graduação da UFPR e de outras universidades de Curitiba, funcionárias da Pró-Reitoria de Gestão de Pessoas, professoras e ativistas de movimentos pela igualdade de gêneros de fora da universidade. A diversidade de público nos surpreendeu: esperávamos encontrar ali as alunas de graduação de ciências sociais que haviam comparecido em peso à reunião com o MP, mas formou-se um grupo diverso, com estudantes que vinham de cursos como Educação, Secretariado, Enfermagem, Design, entre outros. A presença de funcionárias da UFPR e pessoas de fora da instituição apontava para a abrangência da questão, além de lembrar-nos do papel social da universidade no enfrentamento da violência e da intolerância junto à comunidade.

No primeiro encontro, a temática da conversa era "Sexualidades e Cultura do Estupro". Após a revisão de alguns conceitos clássicos dos estudos de gênero (como identidade de gênero, orientação sexual...) através de vídeos e imagens de linguagem não acadêmica, o debate tomou corpo e se aqueceu em torno do papel dos homens na reprodução da violência sexual, e na solução desse problema. Representantes de um coletivo feminista de alunas contaram serem julgadas por suas posições "radicais", de acolhimento às vítimas e "escracho" dos agressores. Seus colegas diziam que elas "afastavam" homens possivelmente simpatizantes de suas causas ao adotarem atitudes como essas.

Quando o debate apontou para o condicionante de gênero presente no comportamento dos agressores, elas responderam, de maneira acalorada, que não era responsabilidade delas acolherem esses homens e mostrarem, pacientemente, que o que haviam feito era errado. "Isso a sociedade já faz! São as meninas que têm medo de encontrar seus agressores, que deixam de frequentar as aulas, os CAs, as festas,

11 Nosso "coletivo" é composto por: Fernanda Azeredo de Moraes (autora), mestra em antropologia e então professora substituta do Departamento de Antropologia da UFPR; Lennita Rugi, mestra em sociologia e professora efetiva do Departamento de Educação da UFPR; Amélia Siegel Corrêa, na época pós-doutoranda em Sociologia na UFPR; e Mariana Corrêa de Azevedo, doutoranda em sociologia na UFPR.

12 Pois, como colocam Carla Gomes e Bila Sorj (2014) sobre o feminismo no Brasil: "Em vez de pensar as mobilizações como quadros temporais sucessivos, optamos por abordá-las em termos de gerações (Reger, 2014), o que possibilita considerar diferentes grupos de feministas ativos simultaneamente, mantendo relações de cooperação e disputa. De fato, o feminismo sempre foi um movimento descentralizado, constituído de diferentes grupos de mulheres, com variadas experiências de vida e modos diversos de conceber o tema das relações de gênero, de formular ideologias e estratégias políticas" (p. 436-7) 
que abandonam o curso. Se nós não excluirmos esses caras, quem vai fazer isso?". Sobre o papel adotado por esses coletivos, a fala de uma integrante do Coletivo Aurora é elucidativa:

Quando eu entrei no Aurora, o que o Aurora fez comigo foi desconstruir. Porque naquela época a gente fazia reunióes que a gente pegava textos não acadêmicos, textos de blogs, e a gente discutia coisas. E nesse sentido eu mudei a minha postura em relação ao mundo, eu era uma mulher feminista, mas eu não tinha consciência de que eu era feminista. Aí, agora, nessa fase que aconteceram todos esses problemas, eu vi que o Aurora foi muito importante para muitas mulheres conseguirem pela primeira vez na vida falarem o que aconteceu com elas, que foi o caso de muitas meninas da história. Pessoas que já foram para psicólogos, já foram para vários lugares, mas nunca se sentiram acolhidas o suficiente para falar sobre o que elas passaram. E muitas delas sempre falam assim "'todas as vezes que eu tentei falar sobre o que aconteceu comigo, eu fiquei com medo que as pessoas julgassem, do tipo você foi culpada...” E quando a gente fez a reunião do coletivo elas sabiam que ali naquele ambiente, por todas estarem no coletivo, por todas terem uma consciência feminista, ninguém ia julgar elas do tipo "você estava com uma roupa inadequada". Acho que isso foi bem importante.

Se produz assim nos coletivos uma horizontalidade ausente a outros momentos da vida universitária, marcada por hierarquias entre veteranos e calouras, professores e alunos, graduandos e pós-graduandos. Observa-se que o feminismo jovem e universitário tem por foco a atuação direta sobre disputas cotidianas. Distancia-se, assim - ao menos em suas práticas - do feminismo acadêmico, que procura compreender o quadro amplo das relações de gênero. "Nosso papel não éo de educar homens, mas de acolher e empoderar mulheres", diziam as alunas.

Parece claro o caráter de urgência que constitui a identidade desses coletivos feministas universitários - coletivos que se fortalecem em atividades cotidianas de apoio, acolhimento, atenção e defesa. Usando de seus próprios termos, através da "sororidade". E isso não é exclusividade da UFPR. Em uma reportagem da revista Piauí sobre os casos de violência sexual denunciados na USP, lê-se:

É nos coletivos de minorias (LGBT, feministas e negros) em construção nas universidades que os estudantes têm encontrado amparo, sobretudo após a onda de hostilidade que enfrentam ao tornarem públicas as denúncias. O coletivo feminista Geni, que Ana Luiza ajudou a fundar, articulou-se na faculdade depois que uma denúncia de violência sexual foi tratada com descaso pelas autoridades acadêmicas. Esse grupo já ouviu relatos de nove estupros ocorridos entre 2006 e 2014 na FMUSP. (Delgado 2015)

De modo significativo, nossa Roda de Conversa sobre Cultura do Estupro foi fechada com a intervenção impactante de um participante homem, de terno e gravata, que tinha até então permanecido em silêncio. No começo de sua fala, o pós-graduando pediu licença para tomar a palavra, dizendo não querer roubar o protagonismo de um movimento do qual ele não é o foco. Afirmou também estar em total acordo com as estudantes que haviam falado anteriormente sobre o seu papel enquanto feministas dentro do cenário universitário. Após conquistar um lugar de fala e escuta com esses argumentos, ele narrou uma experiência pessoal de violência sexual crônica, ao longo de sua infância, perpetrada por um vizinho. Falou sobre as consequências que o estupro tinha acarretado na sua identidade, nas suas relações familiares e afetivas, contou das dúvidas que sentia na juventude sobre o que essa experiência 
faria dele quando um homem adulto (“Um estuprador? Um homossexual? Um suicida?”). Após esse relato, sentindo-nos sem palavras, fechamos o encontro.

É importante frisar o ponto que, desde o começo, tomamos como fundante para a construção das rodas de conversa: o entendimento do gênero como um sistema relacional que abrange homens e mulheres em igual medida. Refletir sobre as masculinidades, seus potenciais opressivos ou libertadores, não é o papel do feminismo dos jovens coletivos, como foi bem colocado pelas estudantes. Diante da omissão das instituições, elas já enfrentam uma demanda extenuante de apoio e mobilização. Entretanto, pensar sobre a masculinidade é uma exigência premente para o feminismo e os estudos de gênero enraizados na academia, além de um tema particularmente interessante para práticas pedagógicas no enfrentamento à violência sexual.

Com esse ideal em mente, planejamos dedicar o segundo encontro das Rodas de Conversa sobre Violência Sexual ao tema das masculinidades. Para abordar sociologicamente o tema da violência sexual é preciso provocar a reflexão sobre a masculinidade, a identidade socialmente construída do sujeito que, na esmagadora maioria dos casos, perpetra a agressão. Tratar desse ponto nos coloca na situação delicada de refletir sobre identidades, ideais e histórias, sem por isso justificar agressões e violências, sem destituir a responsabilidade e o caráter de escolha inerente aos comportamentos abusivos. É o trabalho de apontar para as construções sociais, suas consequências práticas e, principalmente, para a agência que temos frente a elas.

Recuperando a discussão sobre identidade de gênero do encontro anterior, propomos uma reflexão sobre as transformações dos estereótipos femininos diante da permanência dos estereótipos e, consequentemente, dos ideais de masculinidade. Problematizamos a ideia do "Homem" como sujeito universal, os ideais de masculinidade vigentes (competitividade, agressividade) e as consequências estatísticas que podem ser relacionadas a esse sistema (maior população carcerária, menor expectativa de vida). Em uma rodada final de comentários, um aluno do curso de design aludiu, em suas próprias palavras, a necessidade e novidade da discussão: "Eu nunca pude falar para um amigo 'Pô, sabe esse negócio de ser machão e tal? Então, nem acho da hora isso."

Com um público majoritariamente feminino, foi interessante trazer para a discussão valores românticos heteronormativos e o papel que eles ocupam na reprodução de relações de gênero marcadas pela violência, dependência e desigualdade. Algumas participantes do encontro anterior haviam sugerido a importância da discussão sobre o consentimento. Utilizando de um paralelo com a cultura do sadomasoquismo, debatemos a importância do "sim" (no lugar de "não ouvir um não") e o valor do cuidado. Após problematizarmos ideais de gênero (masculinidade) e de relacionamento (dentro de um modelo romântico e heteronormativo), resta para a nova geração a tarefa mais difícil: a de elaborar novas formas de excitação e sensibilidade que pautem os relacionamentos não abusivos.

\section{Respostas Institucionais}

Nosso último encontro das "Rodas de Conversa sobre Violência Sexual" teve como tema participação e empoderamento. Nessa oportunidade, elaboramos diretrizes para uma carta coletiva que 
representasse a visão do grupo, com sugestões e demandas para a Universidade. Ao mesmo tempo em que encerrávamos nosso ciclo, eram promovidas pela reitoria da UFPR reuniões junto à comunidade acadêmica, professores e coletivos feministas, como forma de responder às denúncias ainda estampadas nos muros.

O clamor para que a universidade tomasse uma posição clara contra a violência velada do seu cotidiano já vinha de antes: desde 2014, processos por racismo de professor@s contra alun@s correm dentro e fora da UFPR, com envolvimento do Ministério Público Estadual nessas investigações. $\mathrm{O}$ escancaramento das relações sexistas, homofóbicas e violentas aumentava a pressão para uma reação institucional consistente, que atendesse as demandas do alunado e dos coletivos negros, feministas e LGBTs da universidade.

A resposta foi rápida, porém ardilosa em seu formato: em agosto de 2015, sob o mote \#UFPRparaTodasasGentes, foi inaugurado o portal online "Conte Conosco", destinado à denúncia de agressões e acolhimento de vítimas de violência e descriminação. Nas palavras do então Vice-Reitor, a intenção da ferramenta de diagnóstico e intervenção é deixar claro que a UFPR "não tolera violência". Na primeira página do portal, lia-se:

"A UFPR acredita que o respeito é parte inseparável do senso crítico e da dignidade humana. Acredita que uma universidade deve formar cidadãos, não só profissionais. Acredita que seus valores devem expressar a certeza de uma sociedade mais justa e solidária. Acredita no ser humano e em nossa capacidade de transformar. A UFPR convida você também a acreditar. Por esta ação pioneira, comunidade acadêmica e sociedade uniram as vozes para que pudéssemos falar, sem medo ou preconceitos, sobre o que foi calado durante tanto tempo. E este é só o começo. Esta é a oportunidadeque a universidade mais antiga do Brasil abre para os espaços que se dizem de ensino também se abram ao aprendizado de que transformação social só acontece quando compreendemos as riquezas e as especificidades da diversidade humana. \#ConteConosco" (http://www.conteconosco. ufpr.br/ acessado em dezembro de 2015)

$\mathrm{Na}$ aba "conceitos" existente no portal, encontra-se uma tipologia de violências retirada da Organização Mundial de Saúde ${ }^{13}$ que fala de "atos terroristas e violência de hordas (...) guerra e conflitos violentos a ela relacionados, violência do estado...". Foi impossível encontrar no portal os termos "sexismo" ou "racismo", muito menos "homofobia" ou "transfobia". A violência a ser combatida, de acordo com o portal da universidade, é despida de seus matizes sociais, apresentando-se como uma massa amorfa, desconectada das relações de exclusão e opressão presentes no cotidiano da UFPR, e denunciadas pelas suas alunas.

O formulário a ser preenchido pel@ denunciante, onde além das informações de contato, local da violência e posição na comunidade universitária, existe a pergunta "Estupro? Sim ou Não. Precisamos saber para que possamos the atender o mais rápido possível!". Como discutido acima, de que forma um conceito definido de maneira nebulosa no senso comum pode ser usado instrumentalmente para denúncia, sem que haja as informações necessárias para o entendimento e categorização da violência disponíveis na plataforma?

13 Que classifica a violência em: autodirigida, interpessoal, coletiva - econômica, social e política -; de natureza física, psicológica, sexual, ou de privação ou abandono. 
O mecanismo institucional "Conte conosco" parece se reduzir a uma resposta formal, com o intuito de apaziguar a polêmica vigente, e não de enfrentar o problema. Com ele, a universidade falhou em engajar-se e responsabilizar-se pelo que dentro dela ocorre. Assim sendo, alunas, alunos, professoras e professores seguem sobrecarregados com tarefas de apoio, acolhimento e cuidado - para as quais não tem nem preparação, nem autonomia.

\section{Considerações finais}

Em 1924, Virgínia Woolf já denunciava o tradicional e renomado sistema universitário inglês pelo seu caráter androcêntrico, sistematicamente excludente da participação feminina. Se os problemas aqui descritos são frutos da perpetuação de uma cultura universitária machista de raízes históricas profundas, apenas uma pesquisa detalhada poderá dizer. Contudo, é fácil perceber que não descrevemos aqui uma "piora" no comportamento universitário, um declínio das relações para a violência e a opressão. Observamos sim, como afirmado, uma transformação no plano das sensibilidades, das excitações e das normas de relacionamento. Aquilo que antes era ignorado, esquecido, escondido, ou mesmo tido como aceitável, agora salta aos olhos, à internet e às páginas de jornal.

É fato que o problema da violência pode ser enfrentado com a criação de novos canais de comunicação e atendimento institucionais. Contudo, o racismo, o sexismo e as lgbtfobias demandam discussões e posicionamentos que atingem as estruturas da universidade - a meritocracia, a verticalidade das relações, a suposta neutralidade dos sujeitos, a cultura dos trotes. Os acontecimentos acima reunidos, documentam as transformações que ocorrem em instituições de ensino superior com a entrada, cada vez maior, de mulheres como alunas, professoras e funcionárias. Levar a sério as denúncias dessas alunas nos colocam a repensar a universidade como a conhecemos.

Fernanda Azeredo de Moraesémestre em Antropologia Socialpela Universidade
Federal de Santa Catarina (UFSC) e esteve como professora substituta no
Departamento de Antropologia da UFPR nos anos de 2015 e 2016.

\section{REFERÊNCIAS BIBLIOGRÁFICAS}

DELGADO, Malu. 2015. “Na mira do trote: Denúncias de violência entre estudantes põem na berlinda a Faculdade de Medicina da USP”. Revista Piaui. ed. 101. Disponível em: <http:// revistapiaui.estadao.com.br/materia/na-mira-do-trote/> Acesso em: 23/02/2016

GREGORI, Maria Filomena. "Delegacias de Defesa da Mulher de São Paulo e as instituições: paradoxos e paralelismos”. 2006. In: G. G. Debert \& M. F. Gregori \& A. Piscitelli (orgs.). Gênero e Distribuição da Justiça: as delegacias de defesa da mulher na construção das diferenças. Campinas: Pagu/Unicamp. 
GOMES, Carla e SORJ, Bila. 2014. 2Corpo, geração e identidade: a Marcha das vadias no Brasil2. Revista Sociedade e Estado 29 (2).

MALUF, Sônia W. 2006. "Políticas e teorias do sujeito no feminismo contemporâneo". Anais do Seminário Internacional Fazendo Gênero 7, Santa Catarina.

PERSEU ABRAMO, 2010. Mulheres brasileiras e gênero nos espaços público e privado. Pesquisa de opinião pública. São Paulo. Fundação Perseu Abramo/Edições SESC.

WOLF, Virgínia. Um teto todo seu. Tradução de Vera Ribeiro. Rio de Janeiro: Círculo do Livro, 1990. 